\title{
A gestão escolar e O OLHAR PEDAGógico NO COTIDiANO DA ESCOLA: UMA EXPERIÊNCIA DE SUPERAÇÃO DA NÃO APRENDIZAGEM DA LEITURA E DA ESCRITA
}

\author{
THE SCHOOL MANAGEMENT AND A PEDAGOGICAL LOOK AT THE DAILY ROUTINE OF THE \\ SCHOOL: AN EXPERIENCE OF OVERCOMING THE LITERACY DIFFICULTIES
}

LA GESTIÓN ESCOLAR Y LA MIRADA PEDAGÓGICA HACIA EL DIA A DIA DE LA ESCUELA: UNA EXPERIENCIA DE SUPERACIÓN DE LAS CARENCIAS EN EL APRENDIZAJE DE LA LECTOESCRITURA

\author{
Rosane Alves Pretto de \\ Oliveira \\ (iD) \\ Mestre em Educação em Ciências \\ e Matemática (PUCRS) \\ Professora da Rede Municipal de \\ Esteio/RS. Diretora da Escola \\ Municipal de Educação Básica \\ (EMEB) Paulo Freire \\ Discente do Programa de Pós- \\ graduação em Educação - \\ Doutorado em Educação \\ (UNISINOS) \\ rosanepretto@yahoo.com.br
}

\begin{abstract}
Resumo
O presente artigo descreve as ações conjuntas entre professoras e gestora escolar para possibilitar que estudantes superassem a não aprendizagem da leitura e da escrita. Face ao índice de reprovação, divulgado em 2018 no município, demonstrando que cerca de 300 alunos reprovaram no $3^{\circ}$ ano do Ensino Fundamental, surge a preocupação nas escolas em melhorar esse resultado. Nesse cenário, apresenta-se a experiência de uma escola municipal, descrevendo os procedimentos adotados para auxiliar nessa aprendizagem. A partir de grupos de discussão, debatiam-se alternativas e ações a serem implementadas para preencher lacunas na alfabetização de 13 crianças, de dois $3^{\circ}$ anos do Ensino Fundamental que, ao final do primeiro trimestre de 2019, apresentavam-se, ainda, não alfabetizados. No projeto, professoras e gestora escolar acompanharam de perto o processo pedagógico, planejando e desenvolvendo estratégias que possibilitaram a aprendizagem das crianças; promoveram reflexões e mudança acerca da metodologia utilizada para alfabetizar na escola e a prática colaborativa.

Palavras-chave: Gestão Escolar. Alfabetização. Prática Pedagógica
\end{abstract}

Recebido em: 28 de janeiro de 2021.

Aprovado em: 2 de março de 2021.

Como citar esse artigo (ABNT):

OLIVEIRA, Rosane Alves Pretto de. A gestão escolar e o olhar pedagógico no cotidiano da escola: uma experiência de superação da não aprendizagem da leitura e da escrita. Revista Prática Docente, v. 6, n. 1, e009, 2021. 


\section{Abstract}

This paper describes the collaboration between a group of teachers and the principal school in order to help the students to overcome their difficulties in the literacy process. Given the high failure rates of 2018 in the municipality showing that 300 students failed in the third year of elementary school it was necessary to achieve better results. In this scenario it is shown the example of a municipal institution describing the adopted procedures to improve the reading and writing skills. Group meetings discussed alternatives and actions to fill the gaps in the literacy process of 13 children from 2 third-year classes of elementary school, which still showed literacy difficulties. The teachers and the principal of the school monitored closely the pedagogical process planning and developing strategies that supported student's learning; and promoted reflections and changes about the methodology used to teach literacy in school and collaborative practices.

Keywords: School management. Literacy. Pedagogical practice.

\section{Resumen}

El presente artículo describe las acciones conjuntas entre profesoras y gestora escolar para posibilitar que estudiantes superasen el no aprendizaje de lectura y de escrita. Frente al indicador de reprobación, divulgado en 2018 en la municipalidad, que ha demostrado que un promedio de 300 alumnos reprobó en el tercer año de la Enseñanza Fundamental, ha surgido la preocupación en las escuelas en mejorar ese resultado. En ese escenario, se presenta la experiencia de una escuela pública municipal, describiendo los procedimientos adoptados para auxiliar en ese aprendizaje. A partir de grupos de discusión, se debatían alternativas y acciones que deberían ser implementadas para rellenar huecos de alfabetización de 13 niños, de 2 terceros años de la Enseñanza Fundamental que, al final del primer trimestre de 2019 se presentaron aún no alfabetizados. En el proyecto, profesoras y gestora escolar acompañaron de cerca al proceso pedagógico, planeando y desarrollando estrategias que ha posibilitado el éxito de los niños y han promovido reflexiones y cambios en el grupo sobre sus prácticas.

Palabras clave: Gestión Escolar. Alfabetización. Práctica Pedagógica 


\section{INTRODUÇÃOO}

Face aos índices de reprovação relativos ao município de Esteio, no estado do Rio Grande do Sul (RS), divulgados no final do ano de 2018 no Portal QEdu ${ }^{1}$ (2018), demonstrando que cerca de 300 alunos reprovaram no terceiro ano do Ensino Fundamental, surgiu a preocupação, por parte da gestora e professores(as) de uma unidade pública municipal de ensino, em reverter esses resultados. Para tanto, desenvolveu-se um projeto de trabalho com discentes do $3^{\circ}$ ano do Ensino Fundamental, com o objetivo de recuperar a aprendizagem de 13 estudantes não alfabetizados, no período de 24 de junho a 31 de agosto de 2019. Nesse contexto, identificou-se a importância do papel da gestora escolar no acompanhamento do processo pedagógico como mediadora, auxiliando na promoção de ações de impacto positivo, especialmente no desenvolvimento da competência da leitura e da escrita. Assim, liderava o grupo no trabalho e participava na elaboração de ações que pudessem possibilitar às crianças, a aquisição exitosa dessas competências.

O sucesso na aprendizagem dos discentes na educação básica tem sido motivo de debates recorrentes entre pesquisadores da educação, Barbeiro (2019), Fortes (2019), Lima e Montenegro (2019) e Perfeito (2019). Geralmente, essas discussões acabam por apontar culpados, o que não resolve a questão e acaba por criar "ranços", como a desmotivação entre os envolvidos no processo educativo. Os resultados negativos com relação à educação vão além dos municípios, tornando-se um problema nacional. O Índice de Desenvolvimento da Educação Brasileira (IDEB) tem demonstrado a fragilidade do ensino que não tem alcançado os resultados esperados. Diante destas constatações, percebe-se a importância de divulgar experiências positivas com relação a esse tema, especialmente no contexto analisado, quando o número de alunos que não aprendem a ler e a escrever e reprovam ao final do terceiro ano do Ciclo de Alfabetização se mostra alto.

As professoras identificaram lacunas na aprendizagem da leitura e da escrita como obstáculos para que os alunos conseguissem acompanhar o $3^{\circ}$ ano do Ensino Fundamental do ciclo de alfabetização. A infrequência, o déficit de atenção, a falta de dedicação aos estudos, dificuldades de aprendizagem e o precário acompanhamento por parte das famílias, nessa fase tão importante da vida, eram mencionados nos relatos como "dilemas" e "ranços"2 para superar

\footnotetext{
${ }^{1}$ Portal aberto e gratuito, onde são divulgadas informações sobre a qualidade do aprendizado em cada Escola, Município e Estado do Brasil. Por meio do QEdu, toda a sociedade brasileira tem a oportunidade de conhecer melhor a educação no país. https://www.qedu.org.br/\#.

${ }^{2}$ Palavras utilizadas pelas professoras da escola para se referirem a problemas do cotidiano escolar.
} 
as dificuldades dos estudantes. Nessa via, alguns teóricos, entre eles Paulo Freire (1998), Tardif (2007) e Gatti (2013), destacam o quão complexa é a atividade docente que, além do domínio de conteúdo, demanda a compreensão de que seu papel, enquanto educador, não pode se resumir à transmissão de conteúdos e/ou conhecimentos, mas, também, incentivar e possibilitar transformações dos sujeitos, oferecendo-lhes conhecimentos necessários para que possam atuar, intervir e mudar o meio em que vivem.

O objetivo, e ao mesmo tempo desafio, naquele momento, estava em alfabetizar treze alunos do $3^{\circ}$ ano do Ensino Fundamental num período curto de tempo, visando a possibilidade de acompanharem suas turmas em mesmas condições dos seus colegas já alfabetizados, levando em consideração as diferenças e tempos de aprendizagem de cada um.

Nesse contexto, a experiência resultou na análise de uma demanda específica daquela realidade escolar, seguida pela tomada de ações para acelerar a aprendizagem da leitura e da escrita. O problema estava em, como viabilizar o processo de aprendizagem da leitura e da escrita, em tempo recorde, para que esses alunos pudessem acompanhar o $3^{\circ}$ ano, minimizando os prejuízos da alfabetização tardia?

Apresenta-se o conjunto de ações colaborativas entre gestora e grupo de docentes, que buscaram auxiliar no desenvolvimento de habilidades discentes para a leitura e a escrita. Sendo assim, aborda-se a importância do olhar pedagógico da gestão escolar sobre as situações de não aprendizagem na escola, neste caso a não alfabetização, evidenciando uma de suas competências pedagógicas, que é a de "promover a orientação segundo o espírito construtivo de superação de dificuldades e desafios, com foco na melhoria contínua dos processos pedagógicos voltados para a aprendizagem e formação dos alunos" (LÜCK, 2009, p. 93). Dessa forma, assumindo no cenário democrático uma postura ampliada para além do técnicoadministrativo.

A experiência qualitativa descrita neste artigo foi desenvolvida a partir da metodologia dialética que compreende,

A coincidência entre leis do pensamento e as leis do ser, obtidas e verificadas, pela
ação prática dos homens sobre a natureza, servem de base à coincidência entre a
dialética, a lógica e a teoria do conhecimento. Entre as leis do mundo objetivo e as
leis do pensamento não existe uma identidade plena, antes pelo contrário, entre elas
se dá um movimento dialético, um processo dinâmico de mútua elucidação e
explicitação (GAMBOA, 1987, p. 18).

Essa compreensão corrobora para uma análise crítica do objeto em investigação. Dessa ótica, durante os encontros do grupo de discussão, as professoras relataram, planejaram e 
refletiram sobre estratégias, as propostas metodológicas de ensino e atividades a serem realizadas com as crianças. Além disso, estruturaram os passos seguintes da ação pedagógica: o horário e atendimento dos grupos de alunos participantes, a designação das professoras responsáveis pelo acompanhamento e o registro do desenvolvimento do trabalho. A avaliação da aprendizagem foi realizada por meio das testagens dos níveis de alfabetização, conforme consta na proposta pedagógica para o Ciclo de alfabetização - Anos Iniciais da Rede Municipal de Ensino.

Considera-se que o ato de ler e de escrever é a base de conhecimento para toda a vida, sendo um processo contínuo de aprendizagem. Nesse sentido,

Os conhecimentos, crenças e atitudes das crianças sobre a escrita e a linguagem têm sido um importante foco de atenção de pesquisas psicológicas e de intervenções pedagógicas nos últimos anos, tais pesquisas enfatizam, por um lado, que as crianças possuem conhecimentos prévios ao ensino formal, que esses conhecimentos e crenças desempenham um papel importante na aprendizagem, embora, por outro lado, nem sempre sejam adequados (TEBEROSKY, 1997, p. 09).

O tema da aprendizagem da linguagem e da escrita desperta a atenção de pesquisadores há muito tempo. Suas pesquisas têm ajudado a repensar o processo de alfabetização devido às contribuições importantes para a temática. Teberosky (1997) por exemplo, contribui com o pensamento de que deve-se considerar os "conhecimentos prévios" da criança, nos remetendo ao respeito aos saberes dos educandos enquanto suporte para novas aprendizagens. Nesse enfoque, independentemente do método utilizado, a prática do professor é fundamental porque propõe olhar para além do conteúdo e do método. Respeitar os fatos de que a criança já entra na escola com competências linguísticas, e pode aprender em tempos e formas diferentes, continua sendo essencial. Por isso, as reflexões realizadas, a partir dessa experiência investigativa, podem suscitar mudanças de concepções e de práticas curriculares, que são necessárias diante das problemáticas educacionais atuais.

\section{CARACTERIZAÇÃo dOS SUJEITOS PARTICIPANTES}

Participaram da experiência pedagógica 13 alunos do Ciclo de Alfabetização de uma escola pública municipal da região metropolitana de Porto Alegre. A escolha se deu pelo fato de fazerem parte de um grupo de estudantes com dificuldades de aprendizagem no processo de alfabetização. Todos eram alunos do $3^{\circ}$ ano, quatro da turma $\mathrm{A}$ e nove da turma $\mathrm{B}$, dentre os alunos, neste caso, dos treze envolvidos na ação de mobilização para a alfabetização, nove eram oriundos de outras escolas municipais ou de outras cidades. Todos os alunos estavam na idade correta, isto é, oito anos, para frequentar o $3^{\circ}$ ano do Ensino Fundamental, o que parece coerente 
em função da não repetência nos $1^{\circ}$ s e $2^{\circ}$ S anos do Ciclo. Nem todas as crianças estavam no mesmo nível de aprendizagem da escrita, apresentando os seguintes estágios de desenvolvimento segundo Emília Ferreiro (1999): quatro se localizavam no nível pré - silábico, seis estavam no nível silábico e três encontravam-se no nível silábico-alfabético.

O levantamento realizado nos documentos de transferência da secretaria da escola demonstrou que, dos treze participantes, nove eram oriundos de outras instituições de ensino e cinco haviam sido transferidos mais de uma vez durante o curso dos três anos do Ciclo de Alfabetização. Evidenciou-se, ainda, que naquele momento todos moravam próximo à escola, porém, três apresentavam problemas de infrequência.

O grupo que desenvolveu a ação pedagógica foi composto por seis integrantes: a diretora e cinco professoras da escola. A escolha de duas dessas partícipes deu-se pelo currículo, isto é, por possuírem uma larga experiência em alfabetização e pela disponibilidade de carga horária em suas grades de atendimento escolar diário. As quatro profissionais desempenhavam suas funções na alfabetização. Duas eram titulares das turmas dos $3^{\circ} \mathrm{S}$ anos, trabalhando pelo segundo ano na mesma turma, com uma larga experiência no magistério. Dentre as outras duas profissionais, uma estava atuando como professora substituta há três anos, e a outra trabalhava como alfabetizadora no turno da manhã e com o projeto de matemática no turno inverso, o que lhe rendia algumas janelas durante a tarde, um dos motivos pelo qual veio a participar da experiência. A outra profissional atuava no LA, duas vezes por semana, atendia alunos de todas as turmas da escola, nesse sentido foi necessário reorganizar seus horários a fim de priorizar o atendimento aos treze alunos em um dos seus dois dias. No texto passarei a referí-las como professoras 1, 2, 3, 4 e 5 .

As participantes concordaram que os dados fossem aqui apresentados, assinando a carta de consentimento. Os resultados dessa investigação dizem respeito a essa experiência em particular e foram tratados, sistematizados e armazenados conforme necessidade de desenvolvimento no tempo em que ocorreu, com a devolução dos desdobramentos aos interessados.

\section{A geSTÃo ESCOLAR E O OLHAR PEDAGóGiCo PARA A NÃO APRENDIZAGEM dA LEITURA E DA ESCRITA}

Segundo a Base Municipal Comum Curricular de Esteio,

A escola compreende um conjunto de possibilidades que direciona, alunos, professores, funcionários, pais e demais participantes para uma reflexão constante 
sobre o mundo. A escola representa a autonomia, a autoria e o domínio que os alunos devem conquistar para poder ocupar espaços fora dela (BMCC, 2017, p. 31).

Nessa perspectiva, o olhar do gestor escolar para o desenvolvimento do processo pedagógico na escola se torna indispensável para que, juntamente com sua equipe, delineie estratégias e instrumentos que possibilitem o ensino e a aprendizagem de todos. É na reflexão constante sobre o mundo que a comunidade escolar pode promover mudanças nos modos de fazer e pensar a educação. As não aprendizagens estarão presentes o tempo todo, mas entendêlas como parte do processo educacional, pensando e propondo alternativas de superação, passa pela atuação e compromisso da gestão escolar e do corpo docente com o sucesso dos educandos em suas experiências de e com o conhecimento. Ainda, conforme a citação da BMCC, pode-se deduzir que o processo de construção da leitura e da escrita significam a possibilidade de refletir, compreender e transformar o mundo. Tendo em vista que a leitura e a escrita fazem parte das não aprendizagens, muito evidentes no cenário da educação atual, em especial ao final dos $3^{\circ} \mathrm{S}$ anos do Ensino Fundamental, justifica-se a preocupação com tal questão nas escolas.

A BMCC (2017, p. 45) reitera que o Ciclo de Alfabetização determina o início do processo da leitura e escrita no primeiro ano, e a sistematização e aperfeiçoamento desse processo nos outros dois anos subsequentes. Isso viabiliza a continuidade da aprendizagem respeitando o tempo de cada estudante, no entanto é importante ficar atento àqueles que não estão acompanhando e evoluindo em seus conhecimentos. Esse contexto exige uma "atuação participativa da gestão e de todos que fazem parte direta ou indiretamente do processo educacional" (LÜCK, 2011, p. 22). O perfil do professor que vai alfabetizar precisa ser observado do ponto de vista profissional, pois é comum ficar com essas turmas as professoras que sobram no quadro docente. Prever a necessidade de profissionais respeitando os desejos e perfis existentes na escola pode qualificar o trabalho desempenhado na sala de aula.

Acredita-se que a elaboração de uma organização adequada à promoção da aprendizagem situa-se em um ambiente lúdico, com uso de metodologias alternativas para aqueles que não aprenderam, com estruturação de ações efetivas com os recursos disponíveis e o envolvimento de todos. Isso pode promover experiências positivas como a da escola estudada. Constata-se que muitos alunos acabam atingindo o $3^{\circ}$ ano do ciclo de alfabetização ou mesmo o completando sem dominar a leitura e a escrita, muito embora isso seja uma diretriz de documentos normativos nacionais como a Base Nacional Comum Curricular (BNCC). A BNCC (2018) aborda que mesmo a criança tendo contato com práticas letradas ao longo da 
Educação Infantil, espera-se que a alfabetização se complete ainda nos dois primeiros anos do Ensino Fundamental e acrescenta:

Isto significa que a alfabetização deve ser o foco da ação pedagógica. Nesse processo, é preciso que os estudantes conheçam o alfabeto e a mecânica da escrita/leitura processos que visam a que alguém (se) torne alfabetizado, [...] consiga "codificar e decodificar" os sons da língua (fonemas) em material gráfico (grafemas ou letras), [...] envolve o desenvolvimento de uma consciência fonológica (dos fonemas do português do Brasil e de sua organização em segmentos sonoros maiores como sílabas e palavras), conhecimento do alfabeto do português do Brasil em seus vários formatos (letras imprensa e cursiva, maiúsculas e minúsculas), além do estabelecimento de relações grafofônicas entre esses dois sistemas de materialização da língua (BRASIL, 2018, p. 89-90).

Concorda-se que a alfabetização deva ser o foco da prática pedagógica nos dois primeiros anos do Ensino Fundamental, mas os professores ainda relatam dificuldades em atingir esse objetivo devido a uma gama de problemas. Os mais frequentes são: a indisciplina, a falta de interesse dos alunos, a falta de participação da família e as notórias dificuldades de aprendizagem.

Muitas vezes a realidade do cotidiano docente não oportuniza o distanciamento da prática para repensá-la buscando novas alternativas. Por isso, auxiliar os(as) professores(as) na tarefa de alfabetizar é serviço de todos os envolvidos no processo educativo. Dessa forma, entende-se que deva ser um movimento colaborativo, em que corpo docente e equipe gestora tenham o mesmo compromisso em torno do objetivo comum que é a aprendizagem.

Piaget (1977, p. 127) expressa "que a ação é a base para a aprendizagem e que os conceitos são construídos a partir da ação e sobre a ação". Assim, na visão de Piaget, a educação deve priorizar a atividade e a prática. Também, na mesma linha, Paulo Freire (1998) defende que o aprender e o ensinar resultam da reflexão constante sobre a prática. Nesse sentido, toda a construção do conhecimento prevê uma ação, uma prática e uma reflexão a partir dessa prática, logo, desse pensar. No processo de alfabetização isso é fundamental para que se alcance os resultados desejados.

O professor, nessa perspectiva, exerce papel crucial, pois é o mediador aquele que anda junto, que planeja e organiza as ações, as quais serão experimentadas pelos alunos. Esse caminhar junto, segundo Streck (1994, p. 98), "requer uma postura de quem não tem todas as respostas, mas ao mesmo tempo exige a segurança de quem confia no processo e tem os instrumentos para ajudar". Da mesma forma, a gestão escolar tem a responsabilidade de buscar alternativas diante das não aprendizagens a fim de que os educandos e a escola obtenham êxito em seu processo educativo. 
Para tanto é preciso que ocorra uma mudança de consciência sobre e do papel do gestor escolar, colocando em pauta a discussão de visões reducionistas e centralizadoras que se baseiam em uma ótica antiga, burocratizada e de controle sobre as "coisas", as pessoas e as ações.

Assim, compreende-se que:

\begin{abstract}
As questões atuais da gestão educacional são objeto de análise, como, por exemplo, o desenvolvimento de um corpo teórico sobre essa gestão, a mudança de consciência social sobre a escola, a escola como organização social, a visão estratégica sobre a escola, o reconhecimento da importância da gestão educacional (LÜCK, 2017, p. 29).
\end{abstract}

Observa-se que as questões que perpassam a gestão educacional no pensamento da autora, são também as que perpassam a gestão escolar num sentido micro e estão inscritas num cenário contemporâneo, em que as exigências são cada vez maiores, as demandas da escola são crescentes e amplas no que se refere aos aspectos sociais urgentes que se apresentam. Conforme a mesma autora (LÜCK, 2017, p. 32), à gestão cabe, entre outras funções, “[...] promover o desenvolvimento de competências significativas do aluno, tendo como foco as necessidades evolutivas que o mesmo enfrenta e enfrentará, em cada estágio da sua vida, [...] que ele aprenda a compreender a vida, a sociedade e a si mesmo [...]". Desse modo, defende-se uma gestão escolar democrática e comprometida com a elaboração de um projeto coletivo, empenhada com a qualidade e preocupada com a "dinâmica das interações, que em decorrência do trabalho como prática social passa a ser o enfoque orientador da ação do dirigente, executada nas organizações de ensino de forma compartilhada com a equipe” como destaca Lück (2017, p. 38).

\title{
4 Procedimentos Metodológicos
}

A pesquisa foi embasada em Flick (2009, p. 21-22) porque expressa que "a metodologia qualitativa, estuda o conhecimento e as práticas dos participantes, que dirige-se à análise de casos concretos e suas peculiaridades locais e temporais, partindo das expressões e atividades das pessoas e seus contextos locais." Nessa via, a opção por encontros periódicos do grupo, em que se fazia a escuta e registro dos relatos das professoras envolvidas no trabalho e a partir da análise desses, planejava-se as ações seguintes passo a passo. Em sessenta dias foram seis encontros, oportunidade em que as professoras refletiram sobre suas práticas, relataram suas atividades, compartilharam o trabalho desenvolvido com os alunos e apresentaram as testagens que demonstravam o avanço dos estudantes. Esse contexto retrata uma situação muito particular de uma realidade específica, em que a gestão estava compreendida na esfera democrática e 
envolvida com o todo da escola, implementando ações e participando ativamente do e no desenvolvimento do processo pedagógico e administrativo escolar.

Caracteriza-se como um estudo de caso empírico-qualitativo (ANDRÉ, 1984). O grupo era composto por duas professoras, não titulares das turmas de $3^{\circ}$ ano, duas professoras titulares das turmas A e B, a professora do Laboratório de Aprendizagem (LA), que vinha duas vezes por semana na escola para atender alunos de inclusão, e a gestora da escola. É importante constar que não havia uma atuação efetiva e presente da equipe pedagógica, seja orientadora educacional e supervisora escolar, no Ensino Fundamental naquele momento, por motivos que não são pertinentes abordar aqui.

A experiência investigativa ocorreu durante o ano letivo de 2019, após a realização do Conselho de Classe do primeiro trimestre, realizado no início da segunda quinzena do mês de maio, quando constatou-se que 13 alunos dos $3^{\circ}$ s anos não estavam lendo e escrevendo. Esse fato levou à investigação do porquê de tal ocorrência, mas mais que isso, provocou uma reflexão sobre como resolver o problema investindo em algo que pudesse trazer reais possibilidades de aprendizagem, desfazendo as lacunas existentes em um curto espaço de tempo.

O planejamento foi elaborado prevendo o envolvimento direto da gestora que reunia o grupo, auxiliava na elaboração das ações, debatia ideias e avaliava o transcorrer do trabalho. Contavam-se com duas professoras especialistas em alfabetização que, naquele ano, desenvolveram suas atividades em outros espaços da escola, uma como substituta e a outra como suporte (projeto de matemática). A substituta entrava em sala quando havia faltas e, por isso, assumia o grupo de alunos, todos os dias, duas horas por dia. A professora do suporte tinha dois horários livres na semana e atendia àqueles alunos nesses períodos. A professora do LA atendia aos educandos uma vez por semana. As professoras das turmas continuavam seus trabalhos em sala, porém oferecendo momentos de atividades específicas com os alunos em questão.

Nesse contexto, houve a mobilização do grupo para que tomasse para si a tarefa de alfabetizar esses estudantes. Não se cogitava contar com recursos humanos extras, bem como não se dispunha de horas extras para a realização deste trabalho. A intenção era de que, mesmo diante dos desafios que se colocavam, como o tempo e os escassos recursos de profissionais na escola, se organizariam espaços de atendimento específicos para aqueles alunos. É importante salientar que na época não existia o Programa Mais Alfabetização na escola e o LA, no ano de 
2019, funcionou com horário reduzido de duas vezes por semana e atendendo alunos de seis turmas o que, de certa forma, limitava o atendimento no setor.

Definiu-se como objetivos específicos: organizar um grupo de estudo que pudesse implementar a ação pedagógica com os estudantes; reunir periodicamente para refletir sobre suas práticas de ensino, avaliar a proposta de alfabetização e os resultados; planejar o trabalho e horários em que os alunos seriam atendidos; dinamizar o processo de construção da leitura e da escrita a partir de propostas metodológicas diferentes das que estavam sendo utilizadas. Para alcançar o resgate da alfabetização dos estudantes, as professoras lhes organizaram de acordo com o nível alfabético em que se encontravam, focaram o ensino na abordagem da instrução fônica (BRASIL, 2003), uniram essa abordagem à metodologia Fonovisioarticulatória (JARDINI, 2018) e utilizaram fotos da articulação dos fonemas e espelhos para trabalhar a consciência visual dessa articulação.

A pesquisa foi dividida em três momentos: o primeiro tratou de averiguar as matrículas efetivadas no primeiro trimestre, as quais demonstraram que apenas quatro dos treze alunos já eram da escola, e não tinham completado o segundo ano alfabetizados por motivo de infrequência. Essa informação era importante para entender porque os discentes passaram despercebidos, nas avaliações realizadas, no final do ano anterior.

O segundo foi organizar o grupo de estudos da pesquisa com dia e horário de encontros. O trabalho foi estruturado em seis encontros e visava, em cada um, propor reflexões acerca das percepções das participantes sobre a não aprendizagem da leitura e da escrita; sobre métodos de alfabetização; sobre suas práticas de ensino e a respeito dos alunos e suas aprendizagens. A fonte de informações, ou produção de dados, foram os depoimentos/relatos gerados no grupo de discussões entre as seis participantes. Estes encontros ocorriam, em média, a cada quinze dias. Paralelo aos encontros do grupo de pesquisa acontecia a ação pedagógica de resgate da aprendizagem dos discentes. A ação pedagógica teve início logo após o primeiro encontro do grupo de pesquisa e as atividades realizadas foram: montagem da sala com os recursos necessários, a divisão dos grupos de estudantes por nível de alfabetização e elaboração de exercícios conforme as necessidades de cada aluno. Para a ação pedagógica foram estabelecidas metas e um calendário para as aulas e para a testagem de níveis dos estudantes.

No terceiro momento, realizou-se o primeiro encontro do grupo de discussão a fim de apresentar a ideia da ação pedagógica e estimular a reflexão sobre as percepções em relação a não aprendizagem da leitura a da escrita, sobre o papel de cada um no processo educacional 
escolar dos educandos e sobre o que estavam pensando em termos de atividades concretas para a superação do problema no prazo de dois meses.

Com relação a grupos de discussão, Flick (2009, p. 183) "enfatiza que uma das variedades de discussões em grupo é a utilização, como fonte de dados, da discussão sobre um tópico específico em um grupo natural (isto é, existente na vida cotidiana), [...]”. A partir desse entendimento, o grupo partiu de uma situação compartilhada pelos membros participantes, em que estes debatiam por meio da interação e troca de argumentos, possibilidades de avanços no processo de ensino e aprendizagem da leitura e da escrita, refletindo sobre novas perspectivas de como desenvolver metodologicamente a alfabetização. Ao se utilizar as discussões em grupo objetiva-se analisar processos comuns de solução de adversidades no grupo. Para isso, introduzse um problema concreto, e a tarefa do grupo é descobrir, por meio da discussão de alternativas, as melhores estratégias para resolvê-lo, como expressa a citação:

[...] é nas discussões de grupo que ocorrem as correções por parte do grupo- no que diz respeito a opiniões que não estejam corretas, que não estejam socialmente compartilhadas ou que sejam radicais - são disponibilizadas como um meio de validar enunciados e ponto de vista. $\mathrm{O}$ grupo transforma em ferramenta para reconstrução de opiniões individuais de forma mais apropriada (FLICK, 2009, p. 182-183).

As informações contidas nas discussões foram registradas sob a forma de relatos e sistematizadas conforme a ideia dos objetivos específicos do estudo. Após os encontros, os depoimentos eram categorizados, seguindo a relação com tais objetivos e examinados sob a perspectiva da análise textual do discurso (MORAES; GALIAZZI, 2006) em que o foco empírico estava nos relatos dos participantes. Logo, passavam por estudo minucioso, concentrando-se no contexto e nas construções discursivas presentes no conteúdo da fala. Assim, a interpretação crítica dos textos verbalizados pelo grupo, previa não só confrontar e ajustar ideias sobre o problema de pesquisa, mas encontrar pistas que viabilizassem mudanças e indicassem estratégias para alcançar os objetivos previstos. Para a análise dos depoimentos utilizou-se a Análise Textual Discursiva (ATD).

Sobre as categorias de análise em ATD, os autores Moraes e Galiazzi (2006), sustentam que devem respeitar as propriedades a serem observadas em suas constituições; precisam ser pertinentes em relação aos objetivos da pesquisa; surgem a partir das compreensões do autor sobre os fenômenos estudados e, ainda, precisam demonstrar homogeneidade, isto é, definidas a partir de um princípio conceitual comum considerando quatro focos.

O primeiro foco trata da desmontagem dos textos ou unitarização e se realiza em três momentos: fragmentação, unidade de análise e nomeação/título para cada unidade de análise. 
O segundo foco refere-se ao estabelecimento de relações, momento em que ocorre a categorização, ou seja, o estabelecimento de relações e semelhança entre as unidades de sentido. Nesta etapa, denominada Método Indutivo, as categorias podem ser criadas a partir das unidades de análise, comparando e organizando ideias do particular para o geral. Tais categorias emergem da análise do pesquisador bem como de suas interpretações e percepções. No Método de Análise Misto ocorre a elaboração de categorias a "priori", que ao longo do processo analítico são modificadas pelo método indutivo no intuito de aperfeiçoá-las. Outra perspectiva é do Método de Análise Intuitivo que decorre do desenvolvimento de auto-organização, do conjunto de ideias com que se está trabalhando. Nesta fase, podem surgir os insights do pesquisador por pura intuição e devido ao fato de estar profundamente impregnado dos significados dos textos analisados.

O terceiro foco é a "captação do novo emergente", que consiste na identificação do "não dito" em torno das categorizações criadas, também exprimem os insights do pesquisador no processo de análise.

Por fim, o processo de "auto-organizado", em que a interpretação na ATD promove a compreensão de novos significados por meio das reflexões sobre os metatextos que emergem do desenvolvimento de análise.

Neste estudo foi utilizado o Método Indutivo para a categorização, o que resultou em três categorias emergentes que são apresentadas, descritas e analisadas na seção seguinte.

\section{DESCRIÇÃo E ANÁliSe dos RESUltados}

De acordo com a categorização dos depoimentos das participantes e, conforme suas percepções sobre a situação da não aprendizagem da leitura e da escrita, pelos 13 estudantes que participaram da ação pedagógica, identificou-se três categorias emergentes. A percepção sobre a articulação entre a gestão e o pedagógico da escola, para superar as questões das não aprendizagens; a percepção sobre o método utilizado para alfabetizar as crianças; a percepção sobre suas práticas de ensino.

\subsection{Categoria 1: A PerCePÇão sobre a importânCia da ARTiCulaÇão entre A GESTÃo E O PEDAGÓGICO PARA A SUPERAÇÃO DAS NÃO APRENDIZAGENS}

Essa categoria emergiu com frequência na fala das participantes indicando a tendência de que, nem sempre, a gestão e o pedagógico estão articulados para desenvolver um trabalho conjunto no sentido de encontrar soluções para as questões de não aprendizagem na escola. 
Embora exista, atualmente, a diretriz por uma gestão escolar participativa e democrática garantida pela Constituição e pela Lei de Diretrizes e Bases da Educação Nacional (9.394/96), pode-se observar que, nem sempre isso é uma realidade nos sistemas escolares. Isso aparece nos depoimentos das participantes, ainda que de modo implícito quando estas fazem menção à "participação da gestora" no pedagógico, "ao olhar da gestora para os que não estavam aprendendo", ao fato desta "ouvi-las" ou mesmo "discutir os problemas" da escola (PROFESSORAS 3 e 4, Grupo de Discussão dia 23/08/2019, recortes de falas dos depoimentos).

A gestora escolar, ao articular os segmentos em torno de uma ação pedagógica para a superação de dificuldades, demonstrou uma prática democrática, isto é, comprometida com uma educação de qualidade, buscando a equidade de direito às aprendizagens e ao sucesso dos educandos. O modo como foi planejado, organizado e executado o projeto no interior da escola evidencia isso. Para Lück (2012, p. 41), a gestão democrática "ocorre na medida em que as práticas escolares sejam orientadas por filosofia, valores, princípios e ideias consistentes, presentes na mente e no coração das pessoas, determinando o seu modo de ser e de fazer".

Reconhecer a escola como um ambiente heterogêneo, colaborativo, de respeito à diversidade, onde todos são responsáveis pela educação, fez com que o olhar do gestor escolar sobre o pedagógico se mostrasse como uma alternativa capaz de transformar uma situação de não aprendizagem. Compreende-se que essa conduta por parte da gestão escolar deveria acontecer como uma prática comum, afinal o próprio conceito de gestão escolar "traz em si implícito o caráter participativo" (LÜCK, 2011, p. 27). No entanto, o que tem se constatado são práticas de reducionismo, de gerencialismo e centralizadoras que demonstram a falta de coerência entre as ideias e a realidade, o fracasso escolar estampado nas estatísticas e ineficácia da escola (PARO, 2001) e (LÜCK, 2012).

O cenário descrito nas ações realizadas, a organização e as reflexões do grupo de discussão em torno da promoção da alfabetização dos treze alunos, transpareceu as concepções que estavam por trás da prática da gestora escolar no contexto investigado. O depoimento a seguir, comunica o grau de envolvimento da gestora: "A diretora organizou tudo porque ela teve um olhar para as crianças que não estavam aprendendo. Como a gente está sem supervisora, a parceria dela foi fundamental para resgatar a aprendizagem dos alunos, discutindo conosco alternativas e nos ouvindo [...]”. (PROFESSORA 4, Grupo de Discussão dia 23/08/2019). 
Lück (2017) chama a atenção para três aspectos da gestão educacional, dos quais destaca-se um, “democratização como ampliação do acesso e sucesso do aluno na escola". Por esse viés, a prática da gestão escolar democrática precisa estar alinhada com as expectativas contemporâneas e, portanto, com a qualidade do ensino e da aprendizagem. Pode-se pensar que o olhar da gestão escolar deve estar para além do administrativo, localizando-se em um lugar de estranhamento com posições que ressaltam o fracasso, a incapacidade e a impossibilidade. Desse prisma, os depoimentos a seguir contribuem para a compreensão do contexto do estudo.

De acordo com o depoimento da professora 1, da turma A, no conselho de classe do dia (17/05/2019): “[...] eles não conseguem, eu já fiz de tudo, alguns nem eram nossos, chegaram aqui zerados, eu não sei mais o que fazer". Percebe-se a angústia da profissional enquanto falava sobre a situação. A gestora escolar no lugar de ouvinte, concentrava-se no relato da participante a fim de encontrar soluções para o problema que, naquele momento, passava a ser de todos na escola. A atitude de questionar, de pensar junto, de planejar ações com o grupo refletindo sobre a realidade, pode possibilitar à gestora imprimir outros sentidos ao modo de gerir os espaços escolares e, com isso, assumir uma perspectiva democrática, promovendo o acesso e sucesso dos estudantes.

\subsection{Categoria 2: A PeRCEPÇÃo SObRe O MÉtOdo PARA ALFABETIZAR AS CRIANÇAS COMO UM DESAFIO AOS PROFESSORES}

Nessa categoria as participantes mencionaram a questão metodológica utilizada por elas na alfabetização, percebendo-a como um desafio por: 1) ser diferenciada daquela que vinha sendo desenvolvida em sala de aula; 2) possibilitar a aprendizagem a partir da construção de novos significados e sentidos para as crianças; 3) aprender um novo método enquanto o aplicam obtendo resultados positivos; 4) desempenhar um papel fundamental no processo de aprendizagem da leitura e da escrita. Essas percepções estão de acordo com o posicionamento de pesquisadores ao considerarem a Metodologia como um meio essencial no processo de alfabetização, Jardini (2018) e Ferreiro (1999). Assim, por sugestão delas mesmas, se optou pela Instrução Fônica aliada ao Método das Boquinhas.

Uma das ideias foi a de fazer uso de novas propostas metodológicas, conforme chama a atenção a fala da diretora (Grupo de Discussão dia 24/06/2019), "Bem, talvez fosse necessário inovar no método utilizado para alfabetizar”. Decidiu-se, então, adotar a proposta de Instrução Fônica com os alunos, a fim de, como dito antes, oportunizar estratégias diferentes e diversificadas de aprendizagem da língua escrita. As professoras usaram o desenho das 
boquinhas para que as crianças visualizassem a articulação das letras, e espelhos para poderem visualizar a si mesmos no exercício da pronúncia de sílabas e ou palavras. Também, fotografaram as crianças durante os exercícios de articulação com repetição em frente ao espelho.

A proposta da Instrução Fônica, segundo o Plano Nacional de Alfabetização (PNA) (BRASIL, 2019, p. 33), está alinhada às reflexões sobre o processo de alfabetização realizadas pelo Ministério da Educação (MEC), (BRASIL, 2003; 2007), também, no debate realizado pela Academia Brasileira de Ciências (2011) a partir do texto de Chall (1967), que apontam para a perspectiva de a instrução fônica sistemática levar a criança a aprender as relações entre as letras (grafemas) e os menores sons da fala (fonemas). "Fônica" é a tradução do termo inglês phonics, criado para designar o conhecimento simplificado de fonologia e fonética usado para ensinar a ler e a escrever. Não se deve confundir a instrução fônica sistemática com um método de ensino. Ela é apenas um componente que permite compreender o princípio alfabético, ou seja, a sistemática e as relações previsíveis entre grafemas e fonemas (BRASIL, 2003, 2007; ACADEMIA BRASILEIRA DE CIÊNCIAS, 2011; CHALL, 1967, In. BRASIL, 2019).

A partir desse entendimento pelo PNA (BRASIL, 2019), a ação pedagógica desenvolvida na escola está em acordo com o que prevê este documento, concordando com a citação ao apontar que a instrução fônica não é um método, mas um instrumento fonológico que relaciona grafemas e fonemas de forma sistemática. Esse instrumento fonológico, quando aliado ao conjunto metodológico de trabalho do professor pode contribuir para a compreensão do princípio alfabético.

De acordo com Cardoso e Corrêa (BRASIL, 2019, p. 33), “o conhecimento fônico se mostra eficaz quando é explícito e sistemático (com plano de ensino que contemple um conjunto selecionado de relações fonema-grafema, organizadas em sequência lógica)”. Assim, a instrução fônica sistemática no contexto abordado foi aliada ao Método das Boquinhas, também conhecido como Método Fonovisioarticulatório, defendido e praticado em inúmeras escolas, clínicas e em escolas de alfabetização de adultos, que consiste, segundo sua autora em:

[...] por meio de fotos da articulação da emissão instantânea dos fonemas, isoladamente, cada imagem, cada fonema, usada de maneira metodológica e controlada, viabiliza e favorece a conversão grafofonêmica, transformando-a de abstrata e de difícil compreensão, em algo concreto e palpável, acessível a qualquer tipo de aprendiz, posto que todos possuem uma boca. Exatamente essa "apropriação" traduz-se em conhecimento metalinguístico, em prol de favorecer o trabalho na aquisição da consciência fonológica e fonêmica, e, posterior alfabetização (JARDINI, 2018, p. 849). 
Jardine (2018, p. 851) ainda defende que, "para aprender a ler e escrever deve-se acessar processos de fusão entre entradas auditivas, visuais e articulatórias presentes no cérebro”, “[...] o gesto articulatório assume o status central nesse modelo". Desse modo, a possibilidade de acelerar o processo da leitura e da escrita tomou um novo contorno no contexto em que estava sendo aplicado.

No relato abaixo, pode-se observar a verbalização de uma das participantes com relação à questão da metodologia utilizada para alfabetizar as crianças: "eu sempre ensinei assim e sempre deu certo, agora precisamos inventar um novo jeito para ver se dá certo" (PROFESSORA 2, Grupo de Discussão dia 24/06/2019). Um recorte que, de certa forma, demonstra ainda um certo desconforto ao ter que se desacomodar.

Por meio da Metodologia das Boquinhas pôde-se observar que as crianças desenvolvem muito rápido a consciência fonológica, o método aliado à instrução fônica potencializou o processo de aprendizagem. Dos treze alunos participantes da ação pedagógica, apenas um permaneceu em processo, mesmo assim, conseguiu atingir um nível satisfatório em relação ao que se encontrava anteriormente. $\mathrm{O}$ fato de que dos treze alunos não alfabetizados, nove não eram da escola demonstrou que a questão da não alfabetização ao término do $2^{\circ}$ ano do ciclo de alfabetização é recorrente nas escolas.

\subsection{CATEgoria 3: A PERCEPÇÃo SObRe MUdANÇAS EM SUAS PRÁtiCAS de ENSINO COMO UMA NECESSIDADE PARA QUALIFICAR O TRABALHO EDUCATIVO}

Esta categoria emergiu das argumentações das participantes durante a reflexão e análise de suas práticas de ensino tendo a mudança como: 1) forma de desenvolver o processo de alfabetização; 2) na forma de ver e entender as não aprendizagens; 3) registro das evoluções dos estudantes; 3) nas formas e tempos de aprendizagem; 4) consideração dos conhecimentos prévios.

Conforme indica a professora da turma B, "Eles não querem fazer nada, se recusam, não querem aprender" (Grupo de Discussão dia 24/06/2019). Ao se referirem às suas práticas de ensino utilizavam o comportamento das crianças em aula para justificar o fato destas não terem aprendido. A forma de como estavam desenvolvendo o processo de alfabetização pairava sobre a questão da falta de estímulo e participação dos educandos. A afirmação da professora retrata a baixa autoestima, precisavam, então, acreditar em si mesmos e vivenciar experiências positivas de êxito para que pudessem voltar a crer em suas potencialidades. Essa atitude positiva 
dos educandos frente ao processo de aprendizagem passa pela prática de ensino das professoras em sala de aula.

Uma das premissas recorrentes nos encontros era o fato das professoras do $3^{\circ}$ ano não se reconhecerem alfabetizadoras, desejando que os alunos chegassem alfabetizados ao fim do ciclo. Segundo elas, “[...] a obrigação de ensinar a ler e escrever é da professora do $2^{\circ}$ ano”. Os documentos normativos, BMCC e BNCC evidenciam a necessidade de alfabetização no primeiro ano do Ensino Fundamental, compactua-se com a percepção de uma continuidade desse processo iniciado no primeiro ano e, quando isso não ocorrer, é necessário por parte dos docentes do $3^{\circ}$ ano compromisso com o ensino da leitura e da escrita.

Duas das professoras que participaram da execução da ação pedagógica relatam que:

Quando me foi proposto desenvolver o trabalho de alfabetizar e ou resgatar a aprendizagem das treze crianças, do $3^{\circ}$ ano do ciclo de alfabetização, porque apresentavam dificuldades da leitura e da escrita sugeri logo, a proposta fonológica (fonovisuoarticulatório - popular método das boquinhas), pois esta alia inputs neuropsicológicos como: os sons/fonemas e as letras /grafemas às boquinhas/articulemas. Durante o tempo programado, trabalhei com o grupo de alunos usando materiais diversificados, como jogos, audiovisuais, materiais concretos, espelhos, sempre com atividades variadas embasadas nesta metodologia. Neste período foi possível observar que houve uma evolução importante na construção do processo da aprendizagem no que se refere à aquisição da leitura e da escrita. As crianças avançaram nos níveis da leitura quanto da escrita, também tiveram uma melhora na autoestima (PROFESSORA 3, Grupo de Discussão dia 4/07/1019).

Os alunos que participaram da ação proposta pela diretora necessitavam de acompanhamento direcionado e específico, [...] além de dificuldades cognitivas, apresentavam autoestima baixa o que dificultava ainda mais a aprendizagem. $\mathrm{O}$ processo era lento na construção da leitura e da escrita. A maioria dos treze alunos vieram transferidos de outras escolas. Observei que alguns deles possuía muitas faltas que acabavam por prejudicar, interrompendo o processo de resgate oferecido pela escola. Foram trabalhadas atividades envolvendo o som das letras com o alfabeto das boquinhas, criando a consciência fonética. Muito material concreto, jogos de alfabetização, os alunos eram atendidos em grupo e individualmente. Foi realizada uma grande parceria entre mim, a minha colega, a direção e as professoras das duas turmas (PROFESSORA 4, Grupo de Discussão dia 04/07/2019).

Os depoimentos traduzem as experiências que tiveram e que evidenciaram mudança em suas práticas, quando elas relatam do método utilizado, do uso de material diversificado, da forma lúdica com que desenvolveram as atividades usando jogos e materiais concretos. Demonstram, ainda, que estavam comprometidas com a elaboração do planejamento, refletindo sobre as ações que estavam desenvolvendo, engajadas com a proposta. Dito de outra forma, transparecendo um pensar sobre o fazer e de como fazer, esta conduta por si só, já demonstrava indícios de mudança em suas práticas.

A prática de ensino do professor abrange um conjunto de ações que devem ser mobilizadas e orientadas para um fim. É possível pensar que, em via de regra, é um processo 
que parte da reflexão e se encerra nela (FREIRE, 1998). Zabala (2010, p. 16) afirma que "a prática é algo fluido, fugidio, difícil de limitar com coordenadas simples e, além do mais, complexa, já que nela se expressam múltiplos fatores, ideias, valores, hábitos pedagógicos, etc.”. Apesar dessa fluidez e complexidade espera-se um professor com atitude de pesquisador, intelectual, crítico e mediador em sua prática (HERNÁNDES, 1998).

As alfabetizadoras convergiam ao expressar que era necessário "fazer diferente" (PROFESSORAS, Grupo de Discussão dia 08/07/2019). O ponto comum no grupo era a percepção de que o modo como estavam fazendo e desenvolvendo o processo de alfabetização, pelo menos, com aqueles treze alunos, não estava dando resultado. Muitas vezes, conforme diz uma delas: "precisamos olhar para as especificidades de cada um pra entender o que se passa [...]" (PROFESSORA 5, Grupo de Discussão dia 08/07/2019).

Retomando as falas das participantes, vê-se a importância de destacar as ideias que foram sendo disseminadas no grupo, pois segundo elas:

\begin{abstract}
“[...] conhecer os alunos, suas dificuldades permite ajustar as práticas de abordagem metodológica atuando nas necessidades individuais, é difícil alfabetizar da mesma forma a todos sem ver as questões de cada um. $\mathrm{O}$ atendimento em grupos menores possibilitou agir, não em decorrência do que se observa na sala de aula, mas a partir do que se observa em cada criança. Assim, trabalhamos as necessidades individuais no decorrer do processo. Percebendo no que o aluno precisava melhorar" (PROFESSORAS, Grupo de Discussão dia 30/08/2019).
\end{abstract}

Em termos de mudança, as ideias compartilhadas nas discussões do grupo assinalaram uma postura crítica em relação a alguns entendimentos que as professoras passaram a ter sobre suas práticas no dia a dia. Quando mencionam o fato de "conhecer o aluno e suas dificuldades"; "ajustar práticas"; "é difícil alfabetizar da mesma forma a todos"; "do que se observa em cada criança" estão manifestando reflexões que abrangem competências do ser professor. Pode-se considerar que imersa no cotidiano da escola, geralmente com jornadas extensas de trabalho, a professora nem sempre consegue parar e pensar a respeito do seu fazer pedagógico.

O contexto dinâmico da escola exige ao mesmo tempo competência e sensibilidade para observar o que não está funcionando e ousadia para mudar. No entanto, os espaços e os tempos, para desenvolvimento de tais características no grupo, passava pela compreensão da gestão escolar de que a construção de um projeto educacional de qualidade tem a ver com: prover espaços e tempos para discussão; respeito às ideias e diversidade do grupo de professores; construção colaborativa de ações em que todos tenham voz ativa; comprometimento com a dimensão pedagógica; relações; transparência nas ideias e comunicação das mesmas.

Nessa perspectiva as, 
[...] reflexões sobre essa construção institucional e as relações entre os partícipes do processo educativo podem se tornar constitutivas de um valor profissional e da valorização da docência e do docente na convergência de um conjunto de profissionais engajados em finalidades educativas num dado contexto (GATTI, 2013, p. 171).

A finalidade das professoras, que se engajaram na proposta, consolidou-se por meio do trabalho conjunto em que a gestora escolar e as participantes puderam experimentar um desafio que lhes proporcionou reflexões sobre o processo de alfabetização, mas mais do que isso, provocou mudanças e construiu alicerce para uma prática reflexiva e autocrítica. Com reserva, o que nos propomos foi mostrar que existem possibilidades para o enfrentamento das dificuldades encontradas na educação. Não foi ideia apresentar uma receita, mas divulgar uma experiência desafiadora e de superação do fracasso escolar.

\section{CONSIDERAÇÕES FinAIS}

Considera-se que a participação da gestão escolar no processo educacional, na implementação de ações efetivas de resolução dos problemas que se apresentaram no cotidiano da escola foi fundamental. Criou possibilidades de reflexões e avaliação sobre o trabalho desenvolvido, sobre as metodologias de alfabetização e aprendizagem dos alunos, conferindo visibilidade àqueles estudantes no ambiente escolar, que ainda não conseguiram alcançar o sucesso na aprendizagem.

A pesquisa evidenciou que a prática das professoras, muitas vezes, acontece em desacordo com a teoria, o que pode ocasionar a insegurança dos docentes em relação ao processo de alfabetização. Nesse caso, o domínio e conhecimento de outros métodos podem representar alternativas para o ensino da leitura e da escrita na escola, inovar é positivo por vezes, já que nem todos aprendem ao mesmo tempo e da mesma forma, como assinalaram as próprias professoras em suas falas. O trabalho em conjunto as encorajou a experimentar uma metodologia diferente da que vinham desenvolvendo, até então. Isso levou o grupo a constatar que existe uma demanda de formação continuada, a qual precisa priorizar o processo de construção da leitura e da escrita para os profissionais dos três anos do ciclo de alfabetização no município.

Compreende-se que o objetivo primeiro da escola é comprometer-se com o sucesso na aprendizagem de seus educandos, nessa perspectiva a gestão escolar deve primar para que isso se cumpra na íntegra. $\mathrm{O}$ estudo demonstrou que a conexão entre gestão, equipe pedagógica e professoras é condição para o desenvolvimento de ações que viabilizem resultados positivos no 
processo de desenvolvimento educacional, promovendo a qualidade e equidade dos direitos às aprendizagens de todos os discentes.

O trabalho concluiu, ainda, que nem sempre a gestão escolar consegue estabelecer uma postura de parceria em busca de soluções dos problemas do cotidiano escolar adotando, muitas vezes, condutas de cobrança para obter resultados. Os depoimentos demonstraram o quanto foi positivo para o grupo a participação da gestora na condução da ação pedagógica, na tomada de decisões e na organização e articulação dos recursos e processos disponíveis.

Essa experiência viabilizou a reflexão de uma realidade específica, no entanto abre possibilidades para que outros contextos escolares se desafiem a fazer diferente, a propor alternativas diante da não aprendizagem. Finalmente foi possível constatar, ainda que isso não seja mais novidade, que o aluno que não aprende, não é um problema da professora, mas de todos os envolvidos no processo educacional escolar.

\section{REFERÊNCIAS}

ANDRÉ, Marli Eliza. Estudo de caso: seu potencial na educação. São Paulo: Cadernos de Pesquisa, n. 49, maio 1984.

BARBEIRO, Silvana Ruiz. A importância das práticas construtivistas no processo de alfabetização e letramento com foco na leitura e escrita. Revista Científica Multidisciplinar Núcleo do Conhecimento. Ano 04, Ed. 07, Vol. 07, pp. 21-30. Julho de 2019. ISSN: 24480959.

BRASIL. Decreto $n^{\circ} 9.765$, de 11 de abril de 2019. Institui e orienta a implantação do Plano Nacional de Alfabetização. Diário Oficial da União, seção 1, de 11 abril. 2019. Disponível em:http://www.in.gov.br/materia/asset_publisher/Kujrw0TZC2Mb/content/id/71137476/do1e-2019-04-11-decreto-n-9-765-de11-de-abril-de-2019-71137431. Acesso em 10/11/2019.

BRASIL MEC: Base Nacional Comum Curricular. Disponível em: http://basenacionalcomum.mec.gov.br/images/BNCC_EI_EF_110518_versaofinal_site.pdf. Acesso em: 05/11/2019.

BRASIL. Resolução CNE/CP n ${ }^{\circ}$ 2, de 22 de dezembro de 2017. Institui e orienta a implantação da Base Nacional Comum Curricular, a ser respeitada obrigatoriamente ao longo das etapas e respectivas modalidades no âmbito da Educação Básica. Diário Oficial da União, seção 1, 22 dez. 2017.

BRASIL. Lei n. 9.394, de 20 de dezembro de 1996. Diretrizes e bases da educação nacional. Diário Oficial da União, Brasília, DF, 20 dez. 1996.

CARDOSO, Martins Claudia; CORRÊA, Marcela Fulanete. In: Caderno PNA (2019). O desenvolvimento da escrita nos anos pré-escolares: questões acerca do estágio silábico. Psicologia: Teoria e Pesquisa, v. 24(3), p. 279-286, 2008. 
CHALL, Jeanne, Sternlicht. Learning to read: the great debate; an inquiry into the science, art and ideology of old and new methods of teaching children to read 1910-1965. New York: McGraw-Hill, 1967. Disponível em:

https://www.weber.edu/wsuimages/jmitchell/MEDUC\%206355/The\%20Great\%20Debate.pdf Acesso em:10/11/2019.

ESTEIO, Prefeitura Municipal. Base Municipal Comum Curricular: uma construção reflexiva, dialógica e coletiva. Secretaria Municipal de Educação. Porto Alegre: Gênese, 2017.

FERREIRO, Emília; TEBEROSKY, Ana. Psicogênese da língua escrita. Porto Alegre: Artmed, 1999.

FLICK, Uwe. Introdução à pesquisa qualitativa. 3. ed. Porto Alegre: Artmed, 2009.

FORTES, Luis. Lançamento da cartilha da Política Nacional de Alfabetização (PNA). Pátio: Desafios da Educação. 15 de agosto de 2019. Disponível

em:https://desafiosdaeducacao.grupoa.com.br/politica-nacional-alfabetizacao/. Acesso em $10 / 11 / 2019$.

FREIRE, Paulo. Pedagogia da autonomia: saberes necessários à prática educativa. 8. ed. São Paulo: Paz e Terra, 1998.

FUNDAÇÃO LEMANN. QEdu: Taxas de rendimento escolar, Esteio 2018. Disponível em: https://www.qedu.org.br/\# . Acesso em 09/05/2019.

GAMBOA, Silvio Sánchez. Epistemologia da pesquisa em educação: estruturas lógicas e tendências metodológicas. 1987. Tese (Doutorado em Educação) - Programa de PósGraduação em Educação, Faculdade de Educação, Universidade Estadual de Campinas, Campinas, 1987. Disponível em:

http://www.geocities.ws/grupoepisteduc/arquivos/tesegamboa.pdf . Acesso em: 22 out. 2019.

GATTI, Bernadete Angelina. (org.). Valorização da docência e avaliação do trabalho docente. In: GATTI, Bernadete Angelina. O trabalho docente: avaliação, valorização, controvérsias. São Paulo: Fundação Carlos Chagas, 2013. p. 153-176.

HERNÁNDEZ, Fernando. Transgressão e Mudança na Educação: Os projetos de trabalho. Porto Alegre: Artmed, 1998.

JARDINI, Renata Savastano Ribeiro. Fonema ou gesto articulatório: quem, de fato, alfabetiza? Revista Ibero-Americana de Estudos em Educação, Araraquara, v. 13, n. 2, p. 839-854, abr./jun., 2018. E-ISSN: 1982-5587. DOI: 10.21723/riaee.v13.n2.2018.9496.

LIMA, Cirilo Montenegro de. MONTENEGRO, Jilsete Braz dos Santos. Dificuldades de aprendizagem: interfaces entre o ciclo da alfabetização e seus reflexos no ensino fundamental. Revista Científica Multidisciplinar Núcleo do Conhecimento. Ano 04, Ed. 03, Vol. 02, pp. 100-112. Março de 2019. ISSN: 2448-0959.

LÜCK, Heloísa. A Gestão Participativa na Escola. 10ª ed. Rio de Janeiro: Vozes, 2011. 
LÜCK, Heloísa. Concepções e Processos Democráticos de Gestão Educacional. $8^{\mathrm{a}}$ ed. Rio de Janeiro: Vozes, 2012.

LÜCK, Heloísa. Concepções e Processos Democráticos de Gestão Educacional. 9a ed. Rio de Janeiro: Vozes, 2017.

MORAES, Roque; GALIAZZI, Maria do Carmo. Análise textual discursiva: processo reconstrutivo de múltiplas faces. Ciência \& Educação (Bauru), v. 12, n. 1, p. 117-128, 2006.

PARO, Vitor Henrique. Gestão democrática da escola pública. São Paulo: Ed. Ática, 2001.

PERFEITO, Marcia Vânia Silverio; MENDES, Solange Oliveira Alves de; ALMEIDA, Lucinalva Andrade Ataíde. Avaliação Nacional da Alfabetização no contexto escolar um olhar para as concepções docentes e da gestão educacional. SÉRIE-ESTUDOS, Campo Grande, v.24, n. 51, p. 227-248, 2019. Disponível em: https://doi.org/10.20435/serieestudos.v24i51.1160. Acesso em: 21/10/2019.

PIAGET, Jean. The role of action in the developement of thinking. In: OVERTON, WILLIS \& GALLAGHER, Jeanette Marie. Advances in research and theory. New York: Plenumm Press, 1977.

STRECK, Danilo. Correntes Pedagógicas. Rio de Janeiro: Vozes, 1994.

TARDIF, Maurice. Saberes docentes e formação profissional. Petrópolis, Rio de Janeiro: Vozes, 2007.

TEBEROSKY, Ana; TOLCHINSKY, Liliana. Além da alfabetização. São Paulo: Ática, 2002.

TEBEROSKY, Ana. Aprendendo a escrever - perspectivas psicológicas e implicações educacionais. São Paulo: Ática, 1997.

ZABALA, Antoni. A Prática Educativa: como ensinar. Porto Alegre: Artmed, 1998.

\section{Agradecimentos}

Meus agradecimentos aos participantes dessa pesquisa que com suas colaborações puderam contribuir para que a experiência se realizasse com sucesso. Também, por terem disponibilizado seu precioso tempo para as reflexões que auxiliaram na construção textual e possibilitaram novas posturas nos modos e formas de fazer educação. 